\title{
THE EFFECT OF ECLAMPTIC BLOOD UPON THE URINARY OUT- PUT AND BLOOD PRESSURE OF HUMAN RECIPIENTS
}

\author{
By ERNEST W. PAGE \\ (From the Department of Obstetrics and Gynecology, University of Southern California School \\ of Medicine, Los Angeles)
}

(Received for publication December 20, 1937)

The experiments described below were undertaken with two purposes in mind; first, to determine whether the transfer of $400 \mathrm{cc}$. of blood from patients with severe preeclampsia or eclampsia to normal pregnant women would have any effect upon the blood pressure, urinary output, and symptomatology of the recipient; and secondly, by standardization of the procedure, to discover in eclamptic blood traces of postpituitary hormone in excess of the amount which might be present in normal blood.

\section{LITERATURE}

The toxicity of the blood serum in eclampsia has been studied by numerous workers with varying results. Between 1890 and 1895, all workers agreed that eclamptic - blood serum was more toxic to animals than normal serum. The work of Volhard (1) and Schumacher (2) did not support these conclusions. In 1920, Bumm (3) transferred blood from eclamptics to normal humans in amounts up to $1,000 \mathrm{cc}$. "without demonstrating eclamptic poisons or cerebral intoxication" in the recipients. The details are very meager, and he does not mention any observations on the blood pressure or urinary output of these recipients. Lévy-Solal and Tzank (4) believed that the experimental intracardiac injection of serum from eclamptic patients showed a greater toxicity than that from normal pregnancy. Lash and Welker (5) review the literature and conclude from the study of two eclamptics that the blood serum proteins of normal and eclamptic women's blood show no evidence of toxicity after injection of large doses intraperitoneally into mice.

In 1918 Hofbauer (6) advanced the theory that eclampsia is due to an excessive secretion of postpituitary hormone. In 1931, Anselmino and Hoffmann (7) aroused considerable interest with their announcement that ultrafiltrates from the blood of women with toxemias of late pregnancy inhibited diuresis in rabbits in contrast with control experiments. The rabbit, unfortunately, is not an ideal animal for assaying antidiuretic substances, but their results suggested that there was a demonstrable excess of postpituitary hormone in the blood of women with eclampsia or preeclamptic toxemias.

In 1934, with improved technique, Byrom and Wilson (8) and Theobald (9) repeated these experiments independently and obtained negative results. The first writers used the method of Burn (duration of inhibi- tion of diuresis of rats), while Theobald used dogs as test animals. The latter also determined that dosages of postpituitary hormone as low as 0.005 to 0.01 international units would inhibit diuresis in man, and in pregnant women near term. deWesselow and Griffiths (10) and Page (11) have failed to find any increased amount of pressor substances in the blood of patients with toxemias of pregnancy. Hurwitz and Bullock (12) repeated the experiments of Anselmino and Hoffmann and found neither antidiuretic nor pressor substances in toxemic blood. Levitt (13) and Melville (14) investigated the problem with improved methods of extracting antidiuretic substances from blood and agree that their results cannot support the original contentions of Anselmino and Hoffmann.

The normal mechanism of water and saline diuresis and its inhibition is well summarized by Best and Taylor (15). The exact mechanism of the postpituitary antidiuresis, however, is not understood. More recent investigations indicate that the hormone acts directly on the kidney to allow a greater reabsorption of chlorides and water by the tubules. Renal denervation does not abolish the response (Samaan (16)). It is definitely established that several hundred times the minimal antidiuretic dosage is necessary to effect the blood pressure of unanesthetized animals, and since no antidiuretic substances have been found, it is illogical to assume that the hypertension of eclampsia could be due to postpituitary hormone alone. The investigations of Heller and Urban (17), Levitt (13), Melville (14), and others show that the hormone disappears rapidly from the circulating blood after injection, and more slowly from human blood in vitro. It has been demonstrated that the hormone is rapidly adsorbed in varying amounts by different body tissues; liver, kidney, and brain tissue adsorbing far greater quantities than blood or any other tissue. There is a fairly rapid excretion of the hormone in the urine, and Heller and Urban suggest that there is also a specific (?) ferment responsible for its destruction. All of these factors may contribute to its rapid disappearance from the circulation. Following the injection of large amounts of pituitrin into animals, from $1 / 100$ to $1 / 10,000$ of the hypothetical amount present in a measured volume of blood may be recovered after 5 to 10 minutes (the amount depending largely on the method of extraction); while after 30 minutes, no traces of the hormone can be discovered.

Dock and Rytand (18), Collins and Hoffbauer (19), and others have failed to find pressor substances in the blood of animals with experimental renal hypertension, 
while Pickering (20), and Prinzmetal, Friedman and Rosenthal (21) have transfused normal humans with blood from patients with essential and malignant hypertension without observing a rise of blood pressure in the recipient. Since most hypertensive states have many factors in common, these observations are of some importance in the study of eclampsia.

\section{CLINICAL MATERIAL AND METHODS}

In order to detect the presence of antidiuretic substances, an adequate diuresis must be established. This was done by two methods; administering a constant volume (300 to $500 \mathrm{cc}$.) of water by mouth each hour and waiting for a fairly constant high output of urine; and secondly, by giving a very large quantity of fluids by mouth and intravenously at one time to establish a diuretic curve. With the constant volume method, the immediate drop in volume during the hour following the injection of a substance, with a compensatory rise during the second or third hour was interpreted as indicating the presence of antidiuretic substance. With the diuretic curve method, which appears to be more sensitive, the postpituitary solution or blood was given while the urinary output was rapidly increasing. A sudden decrease, with interruption of the curve, indicates an antidiuretic response. In every patient studied, a diuresis was established by one of these two methods.

Five types of observation were made:

1. Small quantities of postpituitary solution were injected to determine the minimal dosage which would interrupt the human diuretic curve.

2. Five hundred cc. of citrated blood from normal donors were administered to study the effects of normal transfusions on the urinary output, especially to discover whether there is any antidiuretic substance present in that amount of normal human blood.

3. Small quantities of postpituitary solution were mixed with $500 \mathrm{cc}$. of normal citrated blood, and allowed to stand at body temperature for varying intervals of time, to determine whether blood would destroy the action of the hormone in vitro.

4. Twenty units $(2 \mathrm{cc}$.) of pituitrin were given intramuscularly to normal donors while the blood was being withdrawn to discover whether the hor- mone could be passed through the donor and exert its antidiuretic effect upon the recipient.

5. Varying amounts of blood were transferred from patients with severe preeclampsia or eclampsia to women who were normal except for secondary anemia. The effects of these transfusions on the blood pressure, symptomatology, and diuretic curves of the recipients were studied.

All of the recipients were women who were bed patients on obstetrical or gynecological services. The number of experiments was limited because of strict criteria for the recipients which included (1) absence of any acute anemia with loss of blood volume or shock or hypotension, (2) good general physical condition, (3) no abnormal urinary findings, (4) normal circulatory system, (5) no dehydration, (6) a definite indication for therapeutic transfusion, and (7) consent of the patient. Several experiments were discarded because a satisfactory diuresis could not be established, and several others because of technical difficulties (loss of a urine specimen due to spill, delay in completion of transfusion because of clotting of the blood, failure to keep the needle in the vein, etc.).

In each patient, a retention catheter was inserted and left in for the duration of the experiment. With the constant volume method, specimens were collected each hour, or every thirty minutes. With the diuretic curve method, specimens were collected every ten minutes (leaving the catheter open), or the rate of output was recorded on a kymograph. With the kymographic recordings, a large cork was floated in a cylinder of such diameter that the addition of $10 \mathrm{cc}$. of urine resulted in a change of $1 \mathrm{~mm}$. on the record. The disadvantage of this method, however, was that the specific gravity could not be determined on the individual specimens, and it was found to be more satisfactory if the observer sat by the bedside, collected the samples every ten or twenty minutes, measured the volume in a graduated cylinder and recorded the specific gravity with a hydrometer, supervised the fluid intake and administration of the blood or postpituitary solution, and recorded the blood pressure at frequent intervals. Urinary output is expressed as a rate in cubic centimeters per hour.

When it was desired to establish a diuretic curve, the patient was given $500 \mathrm{cc}$. of water to drink within 15 minutes, and $800 \mathrm{cc}$. of normal saline intravenously at a very slow rate. No harmful effects were observed from this procedure alone, and there was no significant rise in blood pressure. Diuresis would begin within 30 minutes.

Obstetrical pituitrin (P.D.) containing 10 international units per cc. was used exclusively. In determining the minimal dosage which would exert an antidiuretic response, one unit $(0.1 \mathrm{cc}$.) was mixed with $800 \mathrm{cc}$. of normal saline. The mixture contained 0.0012 unit $(0.0001$ cc.) of the hormone per cc., and this was given intravenously at a rate of approximately 30 drops a minute. As soon as the rate of urinary output fell, the venoclysis 
was stopped, and from the amount given, the dosage of the pituitary extract could be calculated. As noted below, it was found that as little as 0.01 unit would exert a considerable antidiuretic effect.

When the pituitrin was given to the donors, it was injected into the buttocks about one minute before starting the withdrawal of blood. It would take between 12 and 16 minutes to withdraw $500 \mathrm{cc}$. The blood was mixed with $300 \mathrm{cc}$. of saline containing sufficient sodium citrate to prevent coagulation. When citrated blood was not given, the juice of a lemon was given by mouth so that any diuretic action from the equivalent amount of citrate could be controlled. The amount in either case is probably too small to exert any significant effect.

In the cases where blood was transferred from toxemias to normals, an effort was made to withdraw the blood during an acute phase of the disease, particularly when the blood pressure was high. In all instances the blood was started into the recipients' veins within 10 minutes after its withdrawal, and was given at a rapid rate ( 40 to $60 \mathrm{cc}$. per minute). The blood pressure of the recipient had previously been checked every few minutes for an hour to establish a basal level. In five control experiments where normal blood was given, it was found that in the absence of shock with hypotension from hemorrhage, the systolic pressure did not rise more than $10 \mathrm{~mm}$., and there was no change in the diastolic pressure (except for a slight fall in two cases) when $500 \mathrm{cc}$. were given at the same rapid rate.

\section{RESULTS}

Thirty-seven determinations of antidiuretic effects together with blood pressure curves were performed on 28 patients. The data are not suitable for presentation in tabular form, but are summarized below. The more significant results are shown graphically in the accompanying charts. The blood pressure curves are omitted in all but the last group of experiments, for there were no significant changes in any of them. The dosages of postpituitary hormone used were considerably smaller than the minimal dosage required to affect the blood pressure. It was for this reason that the antidiuretic effect of the hormone was chosen to demonstrate the small traces which might be present in human blood.

The two forms of charts presented may appear confusing. When the hourly urinary output is indicated by solid blocks, it indicates that the constant fluid intake method was used, and the hourly intake is shown by unshaded blocks. Where kymographic recordings were made, or where the diuretic curve method was used, the rate of urine flow (cc. per hour) is shown by a simple line graph.

1. The antidiuretic effects of postpituitary hormone. Twelve determinations were made, using various dosages of the hormone. Four characteristic responses are shown in Figure 1. An injection of 0.001 unit intramuscularly produced a questionable decrease in the urinary output in one experiment. However, 0.01 unit produced a

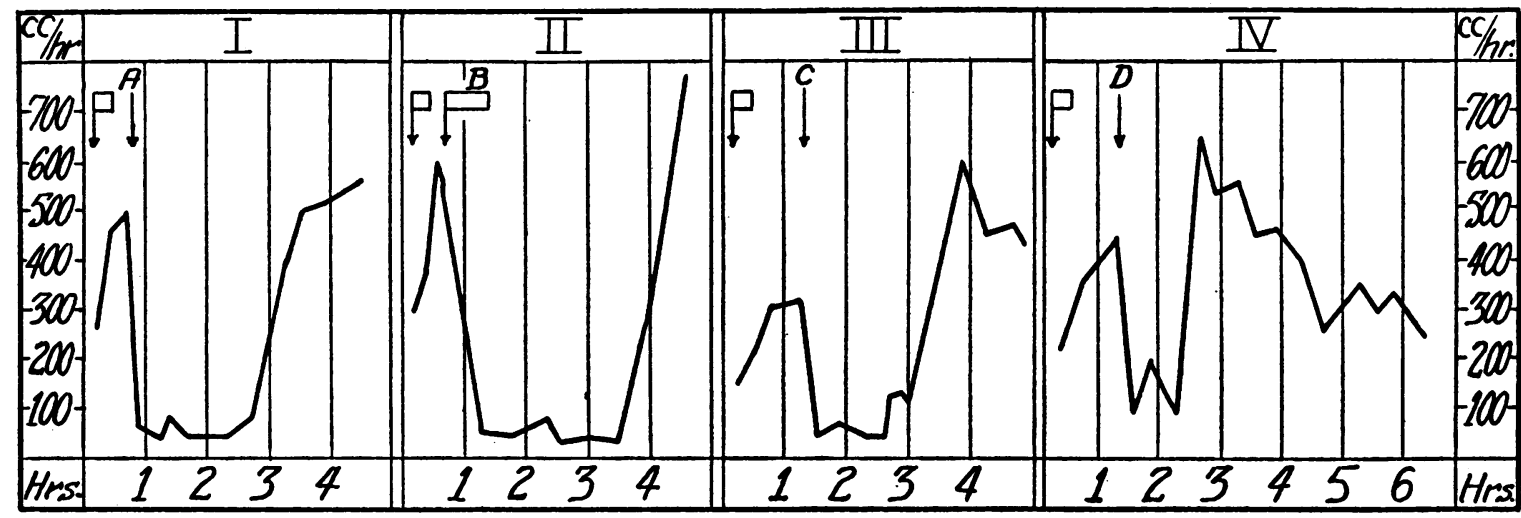

Fig. 1. Effect of Small Quantities of Postpituitary Hormone upon the Diuresis Curves of Four Human SubJects

(Diuresis curves obtained by ingestion of $500 \mathrm{cc}$. of fluids, with addition of $800 \mathrm{cc}$. of normal saline intravenously.)

A. 1.0 unit pituitrin intravenously.

$B .0 .1$ unit pituitrin in $400 \mathrm{cc}$. normal saline intravenously.

C. 1.0 unit pituitrin intramuscularly.

$D$. 0.01 unit pituitrin intravenously.

$\square=$ time fluids given by mouth and intravenously. 
definite antidiuresis lasting for 45 minutes (Figure $1, I V)$. In two experiments, 0.1 unit produced a marked effect lasting from $11 / 2$ to $21 / 2$ hours (when given intravenously). In three experiments, 1.0 unit produced an antidiuretic response lasting from 1 to 3 hours; 0.5 unit produced the same result. Two units were used twice, with similar results, the effect lasting about two hours; 3.0 units were used twice, with immediate and marked antidiuretic action lasting over two hours.

In all cases where amounts down to and including 0.1 unit of pituitrin were used, the rate of urinary flow fell from several hundred cc. per hour to a rate well below $100 \mathrm{cc}$. per hour, and in some instances there would be only 3 to $4 \mathrm{cc}$. of urine secreted during a ten-minute interval. It may be stated with some assurance, then, that any amount of postpituitary solution equivalent to 0.1 unit (and probably as low as 0.01 unit) may be readily detected by these methods.

It would be worth while to mention the details of one case where symptoms developed from the retention of water resulting from antidiuresis. Following the administration of $800 \mathrm{cc}$. of saline intravenously together with 1.0 unit $(0.1 \mathrm{cc}$. of pituitrin) and $500 \mathrm{cc}$. of water by mouth, there was an immediate drop in the rate of urinary output from $600 \mathrm{cc}$. per hour to $20 \mathrm{cc}$. per hour, the antidiuresis lasting for two hours. At the end of this time, she began to complain of severe frontal and occipital headaches, blurring of vision, and she then developed homonymous hemianopsia. She described scotomata which were apparently the same as those experienced by patients with late toxemias of pregnancy. Within 30 minutes, there was a marked increase in the urinary output, with a compensatory rise to a maximum rate of $1,200 \mathrm{cc}$. per hour, and all the symptoms disappeared. At no time was there any rise in blood pressure. The fundi were examined during the symptoms, but no retinal edema was noted.

The adsorption of postpituitary hormone by brain tissue, and the retention of water thereby, is greater than that of any other tissue in the body (17). It would seem almost certain, therefore, that the symptoms in this case were due to cerebral edema. This does not mean, however, that the visual disturbances and headaches experienced with toxemias of pregnancy are due to the action of the same hormone, for water intoxication alone, or any other cause of cerebral edema may produce similar symptoms.

2. The effects of normal transfusions on urinary output and blood pressure. The results of transferring $500 \mathrm{cc}$. of citrated blood from nor- mal donors to patients with chronic secondary anemia were observed on 9 patients. There was no significant rise of blood pressure during the transfusions, except for a brief rise of 10 to 15 $\mathrm{mm}$. $\mathrm{Hg}$ systolic during and immediately after the insertion of the needle. This was interpreted as a pain response.

Half of the amount of blood given was arbitrarily selected as representing fluid intake during that hour. I have not been able to ascertain whether any or all of the blood should be counted as representing fluid intake. The blood, however, does not appear to increase the total urinary output during the next few hours. On the contrary, there is a constant decrease of urinary output during the second hour after the transfusion in all 9 experiments, and I am at a loss to explain this phenomenon. Could it be due to the addition of proteins which increase the osomotic pressure of the total blood stream? Since the effects of postpituitary extract are immediate, this delayed response can hardly be attributed to the hormone.

In four of the nine experiments, however, there appeared to be a slight immediate drop in urinary output (e.g., Figure 2, III and IV). This may be due to the presence of small traces (less than 0.01 oxytocic unit) of pituitrin in the $500 \mathrm{cc}$. of normal blood. Such findings are of significance as controls for the last group of experiments.

3. The effects of in vitro mixtures of blood and postpituitary extract. In six experiments, various amounts of postpituitary extract $(0.12$, $1.0,1.4,2.0,2.0$, and 6.0 units) were added to $500 \mathrm{cc}$. of normal blood and allowed to stand for 30 to 60 minutes at body temperature before giving it to the recipient. In each case, an immediate antidiuretic effect was noted after starting the transfusion. The magnitude and duration of the effect was roughly equivalent to the amount of pituitrin added. Under these conditions, therefore, blood does not completely destroy or inhibit the action of the hormone within the stated time limits.

Figure 3 compares the effect of normal blood with blood to which had been added 2.0 units of pituitrin. The same patient was utilized for both transfusions, and the fluid intake and time intervals were the same.

Figure 4 compares the effect of 0.12 unit of pituitrin in $400 \mathrm{cc}$. of saline with 0.12 unit of 


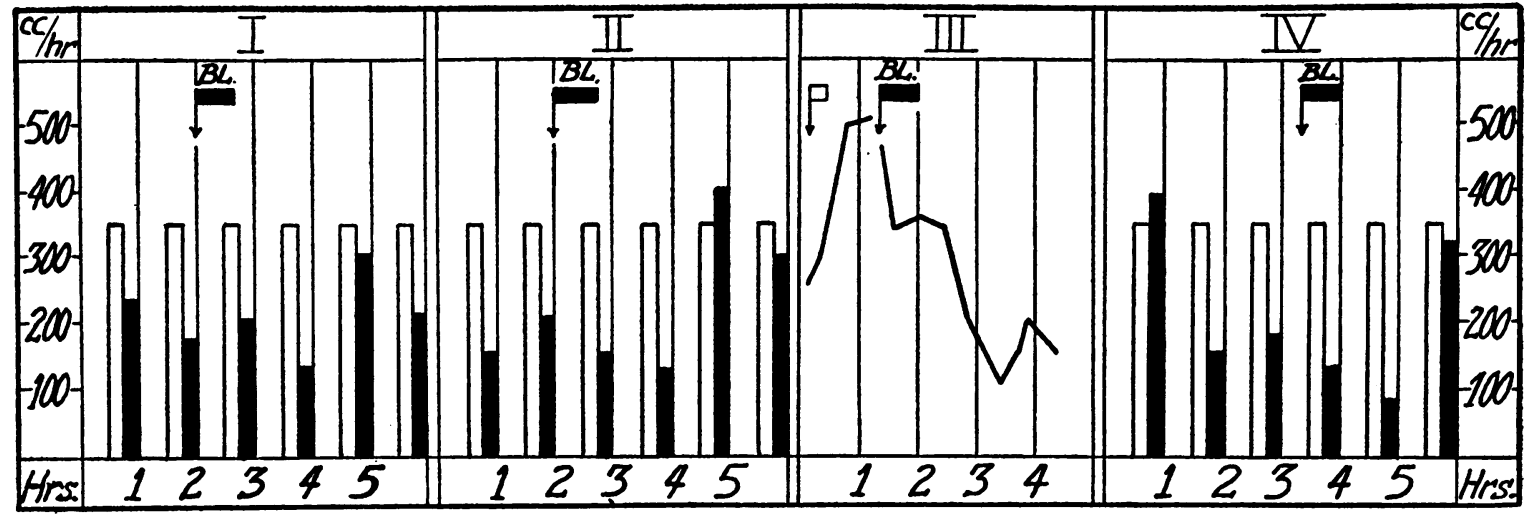

Fig. 2. EfFect of 500 cc. of Normal Blood upon the Urinary Output

(In Subjects I, II, and IV, diuresis was obtained by ingestion of $350 \mathrm{cc}$. of water every hour. In Subject III, 800 cc. of saline were given intravenously at beginning of experiment.)

$\sqrt{\mathrm{BL}} .=500 \mathrm{cc}$. citrated normal blood intravenously.

In II and IV, there appears to be a definite but slight immediate antidiuretic action. In I and III there is a questionable delayed response.

pituitrin in $400 \mathrm{cc}$. of citrated blood on the same patient. The antidiuretic effects are almost identical.

4. The effects of in vivo mixtures of blood and postpituitary extract. There have been only four opportunities for such experiments, and the results are equivocal. Twenty units of pituitrin were given intramuscularly to three male donors at the start of withdrawing the blood. In a fourth experiment, 40 units were given. The height and weight of the donors were obtained and the blood volume estimated. Five hundred cc. of blood were withdrawn during the 15-minute interval following the injection, and given to normal anemic recipients. No immediate antidiuretic effects were noted. In one case there was a marked increase of urinary output, in two others essentially no change except for a slight decrease during the second hour, and in the last experiment there was a slight decrease within the
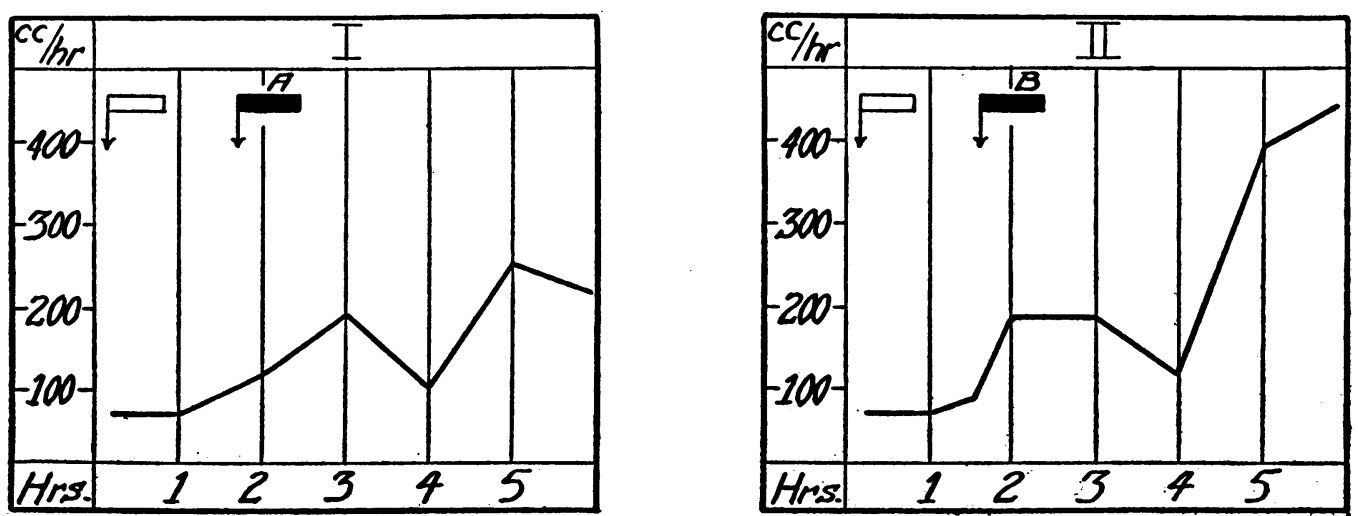

Fig. 3. Effect of Adding Pituitrin to Blood in vitro

I and II same patient; two days between experiments.

$\square=800 \mathrm{cc}$. normal saline intravenously.

$A$. 500 cc. normal blood intravenously.

$B$. $500 \mathrm{cc}$. normal blood to which had been added 2.0 units of pituitrin one hour before. 


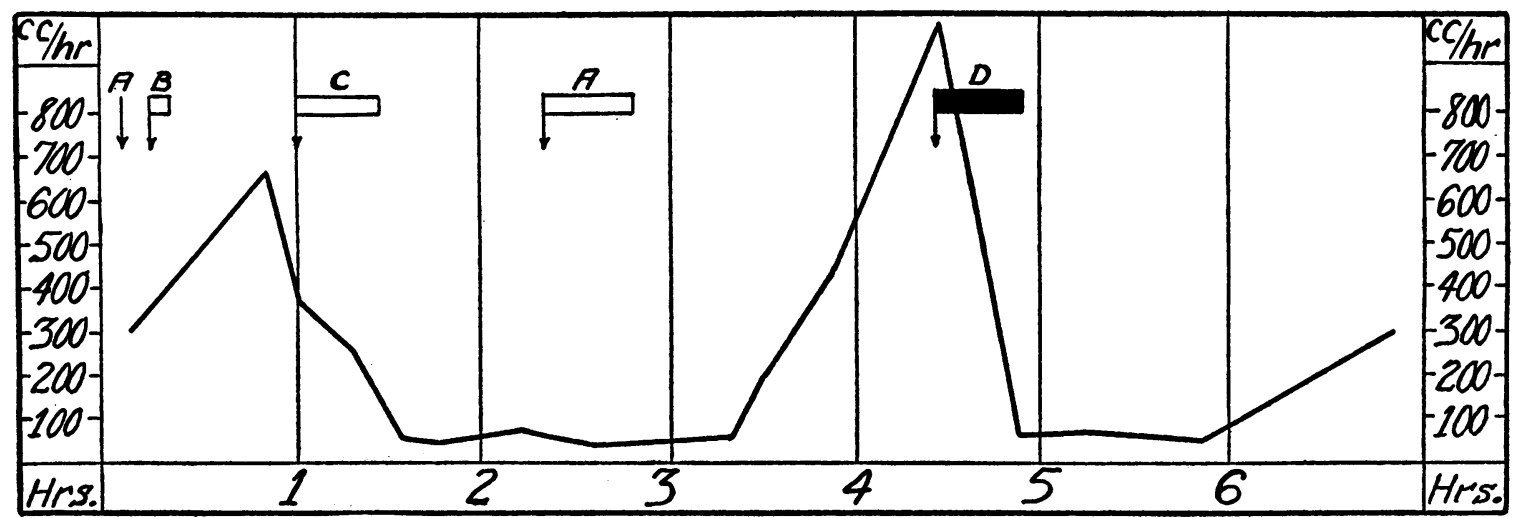

Fig. 4. Effect of Adding Pituitrin to Blood in vitro

$A$. 1000 cc. fluids by mouth.

$B .200$ cc. normal saline intravenously.

C. $400 \mathrm{cc}$. saline containing 0.12 unit pituitrin.

D. 400 cc. blood. 0.12 unit pituitrin added to blood one hour before.

first hour, followed by a marked increase and then a decrease in the rate of urinary output. No conclusions can be drawn. The findings in these four trials, however, are in keeping with the experimental work on animals where the amounts of hormone recovered were but a fraction of the anticipated amounts. This may well be due to the rapid adsorption of the hormone by the various body tissues together with the factor of rapid urinary excretion.

5. The effects of transferring blood from $p a-$ tients with toxemias of pregnancy to normal recipients. Out of seven experiments, there were three failures owing to technical difficulties where the results have been discarded.

In one of the rejected experiments, the blood was withdrawn from a severe postpartum eclamptic four hours after delivery. After receiving $100 \mathrm{cc}$. of the blood, the recipient, who was seven months pregnant, had a severe chill, developed pulmonary edema and cyanosis, with marked tachycardia. A chest plate showed scattered patchy areas of consolidation "suggestive of early bronchopneumonia." The symptoms persisted for 36 hours, then slowly subsided. Although blood was again obtained from both patients and cross-matched without agglutination, the course and symptoms were so characteristic of a transfusion reaction that no significance has been placed by the writer on the fact that the donor had eclampsia. Observations on urinary output were discontinued after the chill. The blood pressure rose during the chill, but returned to a normal level.

The protocols of the four satisfactory experiments are appended to this article. The results are shown in Figures 5, 6, 7, and 8, and are explained with more detail in the case histories. No evidence of any substance with the action of postpituitary hormone was disclosed; the toxemic blood had no pressor action; and no unusual symptoms were elicited by the transfusions.

\section{DISCUSSION}

In the fourth group of experiments, it may be contended that the rapid disappearance of the hormone from the blood stream following a single injection into normal donors would prohibit the opportunity of demonstrating an excess amount of the hormone in eclamptic blood if it were present. This possibility remains. The work of Gilman and Goodman (23) suggests that the body handles the foreign pharmaceutical preparations differently than the natural antidiuretic hormone. They have shown that the stimulus for the production of the postpituitary hormone is dehydration, and that hydration allows destruction of the hormone. In the light of their work, the failure to demonstrate postpituitary principle in the circulating blood may be of little value in ruling out its excessive production and urinary excretion in any human disorder. The theory of Hofbauer, however, assumes a constant, not an intermittent overproduction of the hormone during the height of the disease, and thus the quantity of active hormone present in the blood at any one time should be above normal. Since even the 


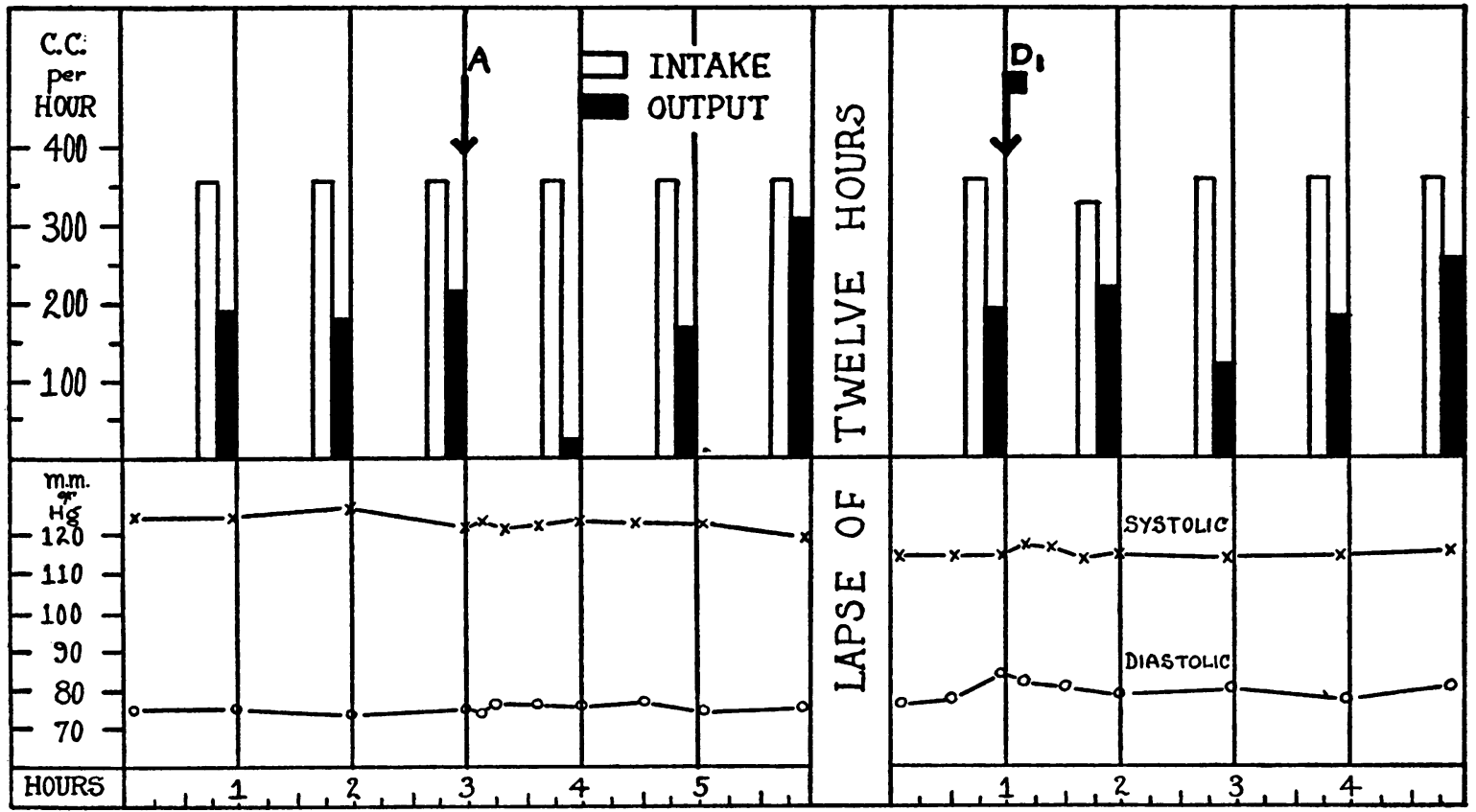

Fig. 5. Effect of Blood from Severe Eclamptic

$A$. 0.5 unit pituitrin intramuscularly (alone).

$D_{1 .} 400 \mathrm{cc}$. blood from Donor 1.

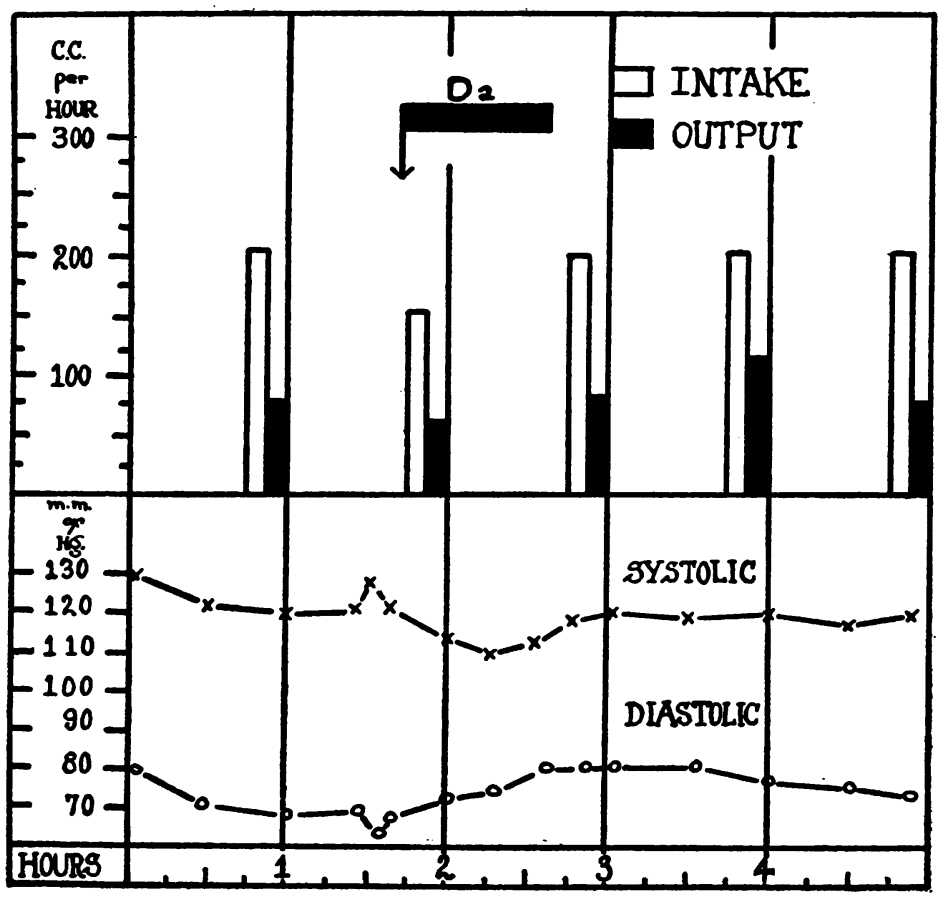

Fig. 6. Effect of Blood from Mind Eclamptic

$D_{2} .400$ cc. of blood from Donor 2. 


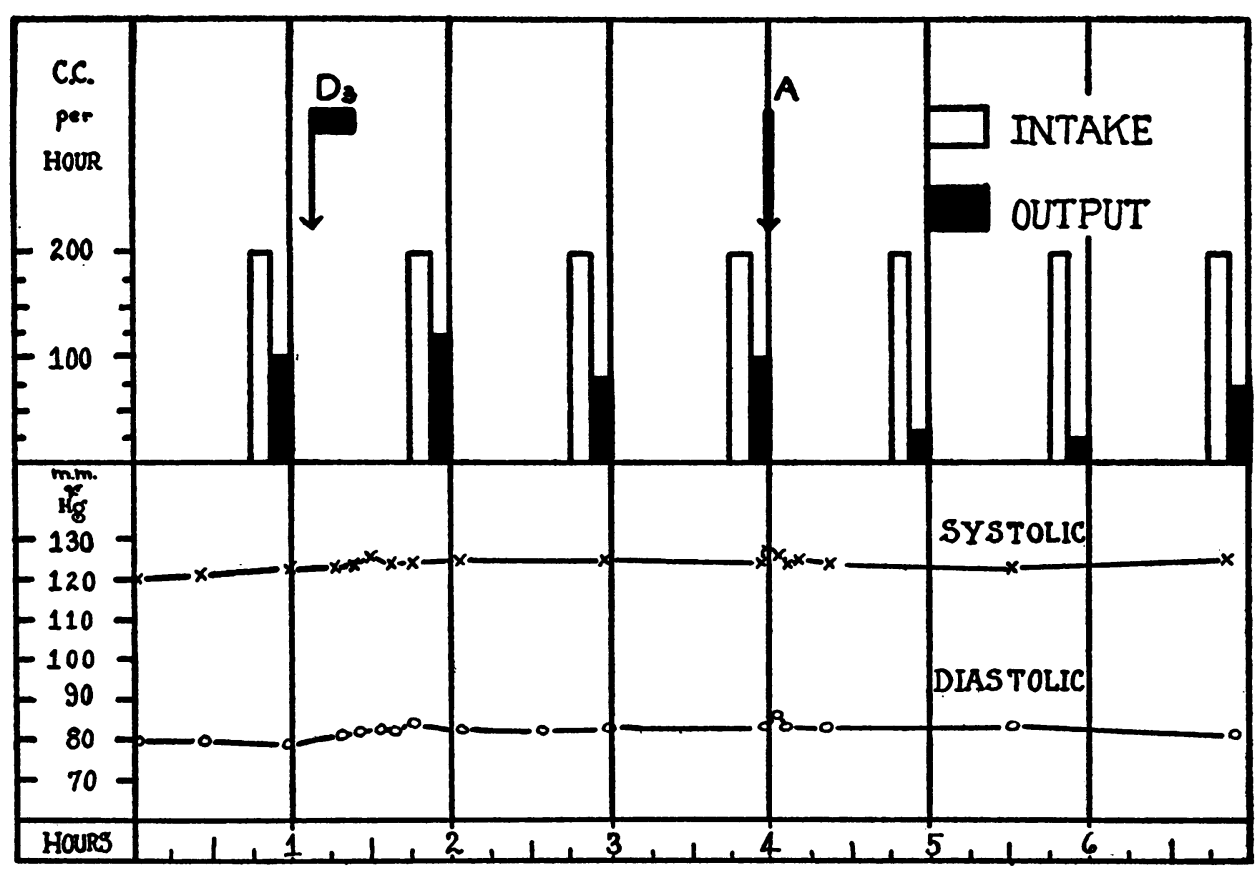

Fig. 7. Effect of Blood from Severe Preeclampsia

$D_{3 .} 400$ cc. of blood from Donor 3.

A. 2 units pituitrin intramuscularly.

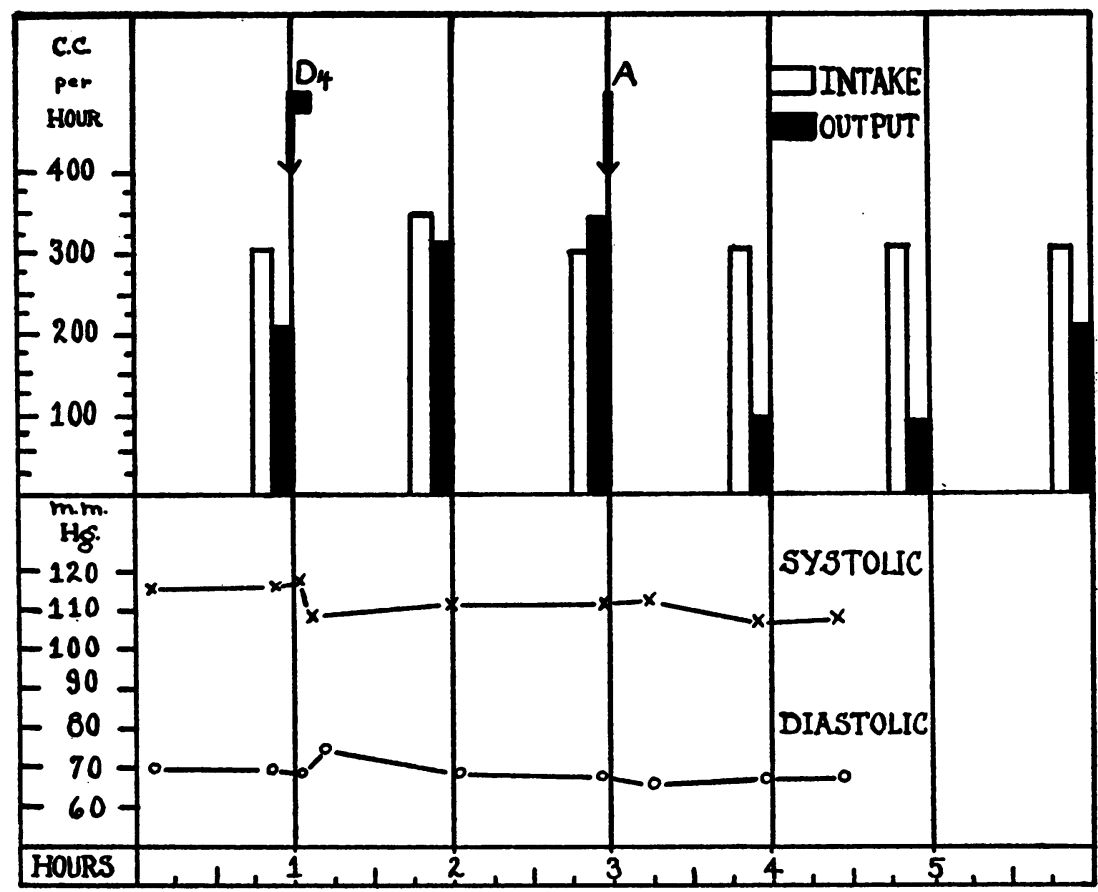

Fig. 8. Effect of Blood from Severe Preeclapmsia (and Probable Preexistent Chronic Nephritis)

$D_{4} .425 \mathrm{cc}$. of blood from Donor 4.

A. 2.0 units pituitrin intramuscularly. 
amounts present in normal blood, particularly if the donor is not hydrated, are probably demonstrable by the methods used, any increased quantity should be detectable.

Small traces of postpituitary principle are capable of producing marked antidiuretic effects in humans. Even large dosages of the same substance rarely raise the blood pressure of normal unanesthetized humans. Since the pressor and antidiuretic substances are apparently inseparable, the failure to detect the antidiuretic principle in eclamptic blood either by extraction and assay on animals or, as in this instance, by direct transfusion to suitably prepared human recipients almost precludes the possibility that the hormone is responsible for the hypertension.

While the number of such operations on human test subjects are necessarily limited, the results are consistent enough to conclude that very small traces of active postpituitary hormone may be detected by these methods, and that such traces are not present in eclamptic blood. The results, therefore, are not in agreement with the conclusions of Anselmino and Hoffmann, but confirm the results of animal experimentation by subsequent workers $(8,9,12,13,14)$.

None of the work brought forward to date (including the present report) actually eliminates the possibility that the hypophysis is in some way involved in the production of the eclamptic syndrome. It is practically certain that the lesions of eclampsia are the result of either a physical or chemical alteration of the blood, and there is much evidence to show that there are endocrine disturbances associated with toxemias of pregnancy (summarized by Shute (22)). Whether the imbalance of sex hormones described in eclampsia is of primary or secondary importance is not known. With our present knowledge of pituitary interrelationships, it is inconceivable that there could be a marked endocrine disturbance without involvement of hypophyseal function. It is possible that the diminished urinary output in eclampsia may be partially or wholly due to a suppression of diuretic substances from the anterior pituitary. It is still possible that an excess of postpituitary hormone is so fixed or adsorbed by other body tissues that it cannot be demonstrated in the blood stream. It can merely be said that the theories of an eclamptic "toxin" or of a hypersecretion of the postpituitary are still attractive, but that they have as yet no valid experimental proof.

\section{SUMMARY AND CONCLUSIONS}

1. Amounts of pituitrin as low as 0.01 unit may be readily detected on suitably prepared human test subjects.

2. Transfusions of $500 \mathrm{cc}$. of blood from normal donors does not result in a significantly altered blood pressure or urinary output in the recipient, although the results suggest the presence of traces of postpituitary hormone in normal blood.

3. If small amounts of pituitrin are added to human blood in vitro and allowed to stand for 30 to 60 minutes before transfusion, a definite antidiuretic response may be obtained in the recipient.

4. If large amounts of pituitrin are given to donors prior to the withdrawal of blood, no definite antidiuretic response can be obtained in the recipient, indicating a rapid elimination or destruction of the hormone from the circulating blood stream.

5. When amounts of $400 \mathrm{cc}$. of blood are rapidly transferred from patients with eclampsia or severe preeclampsia to normal pregnant women, the recipients do not show any rise in blood pressure, interference with diuresis, or untoward symptoms.

6. The results do not support the contention that there is a markedly toxic substance in toxemic blood, nor the theory that there is a hypersecretion of the postpituitary gland in eclampsia. No pressor substance has been demonstrated in eclamptic blood by these methods.

\section{APPENDIX}

Following are the protocols of the cases where blood was transferred from toxemic donors to normal recipients :

Donor 1. Caucasian female, age 29 ; gravida 1, para 0 ; two days from term; referred in by a private physician because of severe headaches for five days, edema of the legs for two weeks, nausea and vomiting for one day, and epigastric pain for one day. Blood pressure on admission was 200/106. The urine showed 6.1 grams of albumin per liter. At 2:00 p.m., the blood pressure was 
$210 / 120$, and at this time $400 \mathrm{cc}$. of blood were withdrawn and citrated. When the needle was withdrawn from the vein at 2:14 p.m., she had her first convulsion. This was followed by a prolonged coma from which she never fully recovered. The pulse rate remained between 140 and 160 . The usual conservative régime was instituted, and the membranes ruptured. Progress in labor was slow. Cesarean section was proposed, but abandoned because of her critical condition. She was delivered of a still-born by low forceps at 7 p.m. the following day, and died a few hours later. At the time of delivery, the pulse was 170, patient had been in a deep coma for 24 hours, and the temperature was $103^{\circ} \mathrm{F}$. Autopsy was refused. Diagnosis: Antepartum eclampsia, severe grade.

Recipient 1. White female, age 21 ; gravida 1 , para 0 ; had been under observation for three days because of a $3 \frac{1}{2}$ months pregnancy with incomplete abortion. General condition was good, and all bleeding had ceased. Hemoglobin was 9.4 grams per 100 cc., red blood count 3.05 million. Twelve hours before the transfusion was given, diuresis was established, and the effect of 0.5 unit of postpituitary extract was determined. There was an immediate and marked antidiuresis as illustrated in the first part of Figure 5. The specific gravity increased from 1.004 to 1.011 . With the compensatory increase in urinary output two hours later, the specific gravity decreased to 1.001 . There was no change in blood pressure.

She received the blood from Donor 1 at 2:20 p.m. the following day (six minutes after completing the removal of the blood). The results are shown in the second part of Figure 5. There was a very slight decrease in urinary output the second hour after receiving the blood, as was noted with normal transfusions. The specific gravity increased from 1.005 to 1.009 and returned to 1.004 with the last specimen. There was no significant change in blood pressure.

In this case, each urine specimen before and after the transfusion was examined microscopically. No abnormal elements were found prior to the transfusion. Following the transfusion, a few red blood cells ( 1 to 2 per high power field in a centrifuged specimen) and some renal epithelial cells appeared. After three hours, these disappeared. Since the sediment was not studied with normal transfusions, no conclusions are drawn.

Recipient 1 had a dilatation and curettage the next day and left the hospital three days later in good condition.

Donor 2. A Mexican female, age 19, gravida 1, para 0 , was admitted to the hospital on the date due, in early, first stage labor. There had been no toxic symptoms prior to admission except for swelling of the feet. The blood pressure on entry was $170 / 120$, and the urine showed $0.42 \mathrm{gram}$ of albumin per liter. On the morning after admission, she complained of headaches, and had a convulsion lasting two minutes, followed by a brief period of coma. Two hours later, $400 \mathrm{cc}$. of blood were withdrawn and citrated. The blood pressure at this time was $150 / 100$. Additional blood removed at the same time for study showed normal values for nonprotein nitrogen, urea nitrogen, and $\mathrm{CO}_{2}$ combining power. The uric acid was $5.1 \mathrm{mgm}$. per cent. A normal delivery of a 5 pound, 7 ounce living infant occurred 10 hours later. There were no further convulsions, and the blood pressure and urine were normal at the time of discharge, and at examination six weeks and six months later. Diagnosis: Intrapartum eclampsia, mild grade.

Recipient 2. The blood removed was immediately transferred to a colored primipara of 19, 4 days postpartum, with moderate secondary anemia resulting from a postpartum hemorrhage. The hemoglobin was 10.9 grams per $100 \mathrm{cc}$. An interesting feature of this observation was that the recipient had a mild preeclamptic toxemia (blood pressure 150/100, $2+$ albumin, headaches and edema) at the time of her delivery, and these symptoms had all subsided before the blood was given. Thus we are certain that this recipient was "susceptible to toxemias."

The results of the transfusion are shown in Figure 6. There was essentially no change in the urinary output or specific gravity. The slight rise of blood pressure at the start of the transfusion was coincident with the insertion of the needle. No subjective symptoms developed during or after the transfusion.

Donor 3. A Mexican female of 20 was admitted because of severe toxic symptoms. This was her second pregnancy. She had had sepsis, but no toxemia with her first pregnancy. Past history otherwise was not significant. She was 8 months pregnant, and complained of swelling of the face, trunk, hands and legs for three weeks, marked visual disturbances with three episodes when she could " see only the right half of a person or a room," and severe headaches. Examination showed generalized edema, with pitting of the lower half of her body. The uterus was $50 \mathrm{~cm}$. above the symphysis, tense, and no fetus could be palpated or fetal heart-tones heard. Blood pressure was 170/110. The urine contained 4.17 grams of albumin per liter, and showed numerous casts and pus cells, with occasional red blood cells. Nonprotein nitrogen was $24 ; \mathrm{CO}_{2}$ combining power 46; uric acid 4.4.

Shortly after admission, a retention catheter was inserted and the hourly urinary output measured. The output during the 8 hours preceding delivery, in spite of a fluid intake of $1,200 \mathrm{cc}$. was only $197 \mathrm{cc}$. (6-24-24 20-8-50-30 and 35 cc. per respective hour). Four hours after admission (i.e., during this period of marked oliguria) $400 \mathrm{cc}$. of blood were removed from the patient and citrated. The blood pressure fell from $175 / 120$ to $150 / 100$.

At the time of delivery, 7,000 cc. of amniotic fluid were allowed to drain off very slowly, and this was followed by the spontaneous delivery of a living premature infant. On the 10th postpartum day, the blood pressure was $150 / 100$ and the urine showed a moderate amount of albumin. At examination 6 weeks later, the blood pressure and urine were normal. Diagnosis: Preeclamptic toxemia, severe grade; and hydramnion. 
Recipient 3. The $400 \mathrm{cc}$. of blood removed from Donor 3 were immediately introduced into a 21 year old Caucasian primigravida who was in the hospital because of an incomplete abortion. Her general condition was good. Hemoglobin was 11.6 grams per $100 \mathrm{cc}$. The results of the experiment are shown in Figure 7. No antidiuretic effect of the donor's blood could be detected, even though the donor herself was having a marked oliguria at the time the blood was taken. There was no pressor action from the transfusion, and the recipient developed no symptoms during or after the transfusion. Note the marked antidiuretic effect of pituitrin (2.0 units) given 3 hours after the blood was given.

Donor 4. A 34 year old white primigravida entered the hospital 11 weeks from term complaining of severe headaches and visual disturbances for two weeks, edema of the ankles for one month, and absence of fetal movements for two weeks. Blood pressure was $160 / 110$. The urine contained 0.83 gram of albumin per liter with numerous casts and pus cells. Blood chemistry values were all within normal limits. Four hundred and twentyfive cc. of blood were removed shortly after admission, and citrated for transfusion. The following day she delivered a $35 \mathrm{~cm}$. macerated fetus and a placenta which was almost completely infarcted. The blood pressure fell to normal, but rose again to $170 / 110$ on the 12 th postpartum day, falling to $150 / 90$ on the 15 th day. $D i$ agnostic impression: Preeclamptic toxemia, severe grade, probably superimposed on a preexistent chronic nephritis.

Recipient 4. The blood was immediately introduced at a rapid rate into a white female of 28 , who had had a normal delivery of her third baby on the preceding day. On admission, her hemoglobin was found to be 7.1 grams per $100 \mathrm{cc}$. and her red blood count 2.98 million, although otherwise the physical examination had not been remarkable. The results of the transfusion are shown in Figure 8. There was a slight drop in the blood pressure and a rise in the urinary output. Note the effect of 2 units $(0.2 \mathrm{cc}$.) of pituitrin two hours after the transfusion. While receiving the blood, the recipient developed numerous large urticarial wheals over the trunk, but there were no other toxic symptoms.

(In addition to the experiments just reported, $500 \mathrm{cc}$. of blood were transferred from a 17 year old girl (nonpregnant) with malignant hypertension (blood pressure $280 / 150$, amblyopia, uremia) to a woman who had just had a postpartum hemorrhage, but who had recovered from her shock. No antidiuretic or pressor response was noted in the recipient.)

\section{BIBLIOGRAPHY}

1. Volhard, F., Experimentelle und kritische Studien zur Pathogenese der Eklampsie. Monatschr. f. Geburtsh. u. Gynäk., 1897, 5, 411.

2. Schumacher, H., Experimentelle Beitrage zur Eklampsiefrage. Beitr. z. Geburtsh. u. Gynäk., 1901, 5, 257.
3. Bumm, Transfusion, Aderlass und Eklampsieblut. Deutsche med. Wchnschr. (Proc.), 1920, 46, 417.

4. Lévy-Solal and Tzanck, A., Nouvelles recherches expérimentales sur la pathogénie et la thérapeutique de l'eclampsie puerpérale; phénomène de choc arret par la pilocarpine. Presse méd., 1923, 31, 669.

5. Lash, A. F., and Welker, W. H., The toxicity of blood serum proteins in eclampsia. Am. J. Obstet. and Gynec., 1928, 15, 511.

6. Hofbauer, J., Die Ätiologie der Eklampsie. Zentralbl. Gynäk., 1918, 42, 745.

Ibid., Recent advances in the study of the etiology and treatment of eclampsia gravidarum. Am. J. Obstet. and Gynec., 1933, 26, 311.

7. Anselmino, K. J., and Hoffmann, F., Die Utbereinstimmungen in den klinischen Symptomen der Nephropathie und Eklampsie der Schwangeren mit den Wirkungen des Hypophysenhinterlappenhormons. Arch. f. Gynäk., 1931, 147, 597.

8. Byrom, F. B., and Wilson, C., Alleged pituitary origin of eclamptic and preëclamptic "toxemias" of pregnancy. Quart. J. Med., 1934, 3, 361.

9. Theobald, G. W., Alleged relation of hyperfunction of the posterior lobe of the hypophysis to eclampsia and the nephropathy of pregnancy. Clin. Sc., 1934, 1, 225.

10. deWesselow, O. L. V., and Griffiths, W. J., On the question of pressor bodies in the blood of hypertensive subjects. Brit. J. Exper. Path., 1934, 15, 45.

11. Page, I. H., Pressor substances from the body fluids of man in health and disease. J. Exper. Med., $1935,61,67$.

12. Hurwitz, D., and Bullock, L. T., Failure to find pressor and antidiuretic substances in patients with toxemia of pregnancy. Am. J. M. Sc., 1935, 189, 613.

13. Levitt, G., The problem of an antidiuretic substance in the blood of patients with eclampsia and other hypertensive diseases with observations on spinal fluid. J. Clin. Invest., 1936, 15, 135.

14. Melville, K. I., Antidiuretic pituitary substance in blood, with especial reference to the toxemia of pregnancy. J. Exper. Med., 1937, 65, 415.

15. Best, C. H., and Taylor, N. B., Physiological basis of medical practice. Wm. Wood and Co., Baltimore, 1937 , pp. 612 to 614 .

16. Samaan, A., The effect of pituitary (posterior lobe) extract upon the urinary flow in non-anesthetized dogs. J. Physiol., 1935, 85, 37.

17. Heller, H., and Urban, F. F., The fate of the antidiuretic principle of postpituitary extracts in vivo and in vitro. J. Physiol., 1935, 85, 502.

18. Dock, W., and Rytand, D. A., Absence of vasoconstrictor substance in blood of rats with renal hypertension. Proc. Soc. Exper. Biol. and Med., 1934, 32, 374.

19. Collins, D. A., and Hoffbauer, F. W., Effect of trans- 
fusion of blood from dogs with experimental renal hypertension into normal dogs. Proc. Soc. Exper. Biol. and Med., 1937, 35, 539.

20. Pickering, G. W., The effect of introducing blood from patients with essential hypertension into other human subjects. Clin. Sc., 1936, 2, 185.

21. Prinzmetal, M., Friedman, B., and Rosenthal, N., Nature of peripheral resistance in arterial hyper- tension. Proc. Soc. Exper. Biol. and Med., 1936, 34, 545.

22. Shute, E., Endocrine background of the toxemias of late pregnancy. Surg. Gynec. and Obstet., 1937, $65,480$.

23. Gilman, A., and Goodman, L., The secretory response of the posterior pituitary to the need for water conservation. J. Physiol., 1937, 90, 113. 